\title{
Use of Reflectance Spectroscopy as a Tool for Screening Viroid-Inoculated Oil Palm Seedlings
}

\author{
Golhani K ${ }^{1}$, Balasundram SK ${ }^{*}$, Vadamalai $\mathrm{G}^{2}$ and Pradhan $\mathrm{B}^{3}$ \\ 1Department of Agriculture Technology, Faculty of Agriculture, Universiti Putra \\ Malaysia, Malaysia \\ 2Department of Plant Protection, Faculty of Agriculture, Universiti Putra Malaysia, \\ Malaysia
}

${ }^{3}$ Department of Civil Engineering, Faculty of Engineering, Universiti Putra Malaysia, Malaysia

\section{Research Article}

Volume 2 Issue 5

Received Date: December 04, 2017

Published Date: December 20, 2017

*Corresponding author: Siva K Balasundram, Department of Agriculture Technology, Faculty of Agriculture, Universiti Putra Malaysia, Malaysia, Tel: +6 03-8947 4896, +6 019-240 7371; E-mail: skbal71@gmail.com; siva@upm.edu.my

\begin{abstract}
Reflectance spectroscopy was assessed as a new diagnostic tool for screening oil palm (Elaeis guineensis Jacq.) seedlings inoculated with Coconut cadang-cadang viroid (CCCVd). This study was aimed at non-destructive diagnosis of Orange Spotting (OS) disease of oil palm under glasshouse conditions. Leaf reflectance (in the detection range of 325-1075 nm) was acquired from oil palm seedlings with and without inoculation (control) of CCCVd. Spectral reflectance was measured at 15 and 30 days after inoculation using a non-imaging spectroradiometer, ASD FieldSpec $®$ HandHeld ${ }^{\mathrm{TM}} 2$. The red-edge region (680-780 nm) was investigated, and two spectral bands (i.e. $680 \mathrm{~nm}$ and $754 \mathrm{~nm}$ ) were selected. Reflectance Sensitivity (RS) analysis was performed over these spectral bands. The far red band at $680 \mathrm{~nm}$ was found to be markedly sensitive to CCCVd infection while the spectral band at $754 \mathrm{~nm}$ was found to be insensitive. The $680 \mathrm{~nm}$ band gave an RS of $35.4 \%$ while the $754 \mathrm{~nm}$ band registered an RS of $-5 \%$. This study demonstrates the potential of screening CCCVd infection at an early stage (nursery establishment) non-destructively.
\end{abstract}

Keywords: Reflectance spectroscopy; Viroids; CCCVd; Orange spotting; Early detection

\section{Introduction}

Viroids are the smallest known pathogens in plants. They are basically naked circular RNA molecules, lacking the protective protein, under the class of sub-viral pathogens that range is size between 246 and 401 nucleotides [1-3]. Viroids inhibit cell growth and shoot development Qi and Ding (2003) [4] either asymptomatically (latent infections) Flores, et al. (2006), Vadamalai, et al. (2006) [5,6] or symptomatically (mild to severe infections) $[2,7,8]$. According to Kovalskaya and Hammond (2014) [9], symptoms developed in viroidinfected host plants are macroscopically similar to symptoms caused by virus infection. Such symptoms include stunting, dwarfing, vein clearing, leaf epinasty, chlorotic or necrotic spots, and malformation of flowers, 


\section{Open Access Journal of Agricultural Research}

fruits and tubers. An extremely virulent strain of viroids can also cause plant mortality. Developments of symptoms are typically subjected to the interaction between viroid strain and host genome. As such, viroid pathogenicity has often been described as a complex phenomenon.

Coconut cadang-cadang viroid (CCCVd; Cocadviroid, Pospiviroidae) is one of the known species of viroids. CCCVd is causal agent of Orange Spotting (OS) disease in the African oil palm, discovered in the early $19^{\text {th }}$ century in West Africa [10]. In the context of Malaysia, for the first time, a 246 nt form of CCCVd variant was found in symptomatic oil palm $\mathrm{Wu}$, et al. (2013) [11], and three different variants of CCCVd i.e. $297 \mathrm{nt}, 293 \mathrm{nt}$ and 270 ntwere found in asymptomatic oil palm [6]. In recent years, many molecular marker techniques have been evaluated for detection of CCCVd in oil palm. For example, the Reverse Transcription-Polymerase Chain Reaction (RT-PCR) Vadamalai, et al. (2006) [6], Ribonuclease Protection Assay (RPA) Vadamalai, et al. (2009) [12], and Reverse Transcription Loop-Mediated Isothermal Amplification (RT-LAMP) [13]. These techniques are destructive as they exploit leaf samples with chemical treatment and consume longer time in laboratory. The proposed supplementary approach of OS diagnosis using reflectance spectroscopy provides a rapid and nondestructive means of screening in vivo at the leaf scale prior to laboratory investigation.

Spectroscopy works on the principle of interaction of solar radiation with leaf surface. Different diagnostic features at ultraviolet, visible, and Near-infrared (NIR) regions of electromagnetic spectrum can differentiate between healthy and diseased plant. For example, visible region absorbs more light due to high chlorophyll content in the healthy leaf, while NIR region reflects more light due to leaf scattering or no absorption [14]. The red-edge region of electromagnetic spectrum $(680-780 \mathrm{~nm})$ which is located between visible and NIR regions continuously monitors the chlorophyll absorption [15].

Recent reports indicate that emerging incidences of OS disease in oil palm trees could potentially result in a significant reduction in palm oil production. A plausible intervention to this problem is to eliminate infected oil palm seedlings at the seedling stage. This approach can be realised using a hand-held spectroradiometer to screen infected oil palm seedlings at the onset of latent infection. This study was performed with the aim of assessing the spectral reflectance of CCCVd-inoculated oil palm seedlings, and to determine the reflectance sensitivity of the relevant spectral bands.

\section{Methodology}

A glasshouse experiment was conducted using 3monthold oil palm seedlings at Universiti Putra Malaysia, Serdang, Malaysia over a period of four months (February through May of 2015). Highly infective inoculants of CCCVd (variant246 nt) were used for inoculating a total of fifteen oil palm seedlings. Five seedlings were grown uninoculated (control). A spectroradiometer (Model: ASD FieldSpec ${ }^{\circledR}$ HandHeld 2) was deployed to measure leaf reflectance. The reflectance of inoculated and healthy oil palm seedlings was recorded at 15 and 30 days after the inoculation (dai).The spectroradiometer measured reflectance at a range between $325 \mathrm{~nm}$ and $1075 \mathrm{~nm}$ at $1.5 \mathrm{~nm}$ sampling interval with an accuracy of $\pm 1 \mathrm{~nm}$ and a resolution of $<3 \mathrm{~nm}$ at $700 \mathrm{~nm}$. This device comprised a standard for eoptic of $25^{\circ}$ field of view.A50 cm distance was maintained between sensor and target during spectral measurement under clear and sunny outdoor conditions between 11:00 and 13:00 hr.

Spectral data is multivariate in nature. Cluster analysis is a multivariate analysis technique that creates a cluster of similar spectra, also called dendrogram. The scale at top of the dendrogram is known as normalized Euclidean distance which moves at an increasing degree from left to right. Highly relevant spectra were determined using cluster analysis on the basis of minimum Euclidean distance. These spectra were averaged to obtain representative spectra of inoculated and control oil palm seedlings. Cluster analysis was performed using XLSTAT Version2015.6 (Addinsoft, New York, USA).The stresssensitive and stress-insensitive bands were selected from these representative spectra. Reflectance Sensitivity (RS), as proposed by Riedell, et al. (2002) [16], was derived from selected bands. RS was computed as follows:

$\mathrm{RS}=[\mathrm{RD} /$ (Reflectance of diseased leaves) $] \times 100$

Where: RD denotes reflectance difference between diseased leaves and healthy leaves

\section{Results and Discussion}

The dendrograms obtained from spectral readings of inoculated and healthy oil palm seedlings were used to compute the minimum Euclidean distance measured within each interval of spectral measurement. Results found that the minimum Euclidean value was zero between 15V8.mn and 15V9.mn at 15 dai, 2 between 30V7.mn and 30V8.mn at 30 dai (Figure 1). All of these similar spectra were averaged to get a representative spectral signature of inoculated seedlings. As such, in dendrograms of healthy seedlings, seedling sample C3 


\section{Open Access Journal of Agricultural Research}

was selected on the basis of minimum Euclidean distance (Figure 2). 15C3, 15C4, 30C2 and 30C3were averaged to get are presentative spectral signature of healthy seedlings. Representative spectral signatures of inoculated and healthy oil palm seedlings were plotted against a range of wavelengths between $325 \mathrm{~nm}$ and 1075 $\mathrm{nm}$, as shown in Figure 3.0ver the entire wavelength, the red-edge region $(680-780 \mathrm{~nm})$ was specifically inspected. It was observed that reflectance started to increase at 680 $\mathrm{nm}$ and decrease at $754 \mathrm{~nm}$ in both spectral signatures. The first band (i.e. $680 \mathrm{~nm}$ ) was located at far red region, indicating a point of maximum absorption of sun light. The second band (i.e. $754 \mathrm{~nm}$ ) was a first steep slopeat the NIR region (Figure 3). Both these spectral bands were pursued for RS analysis (Figures 1-3).
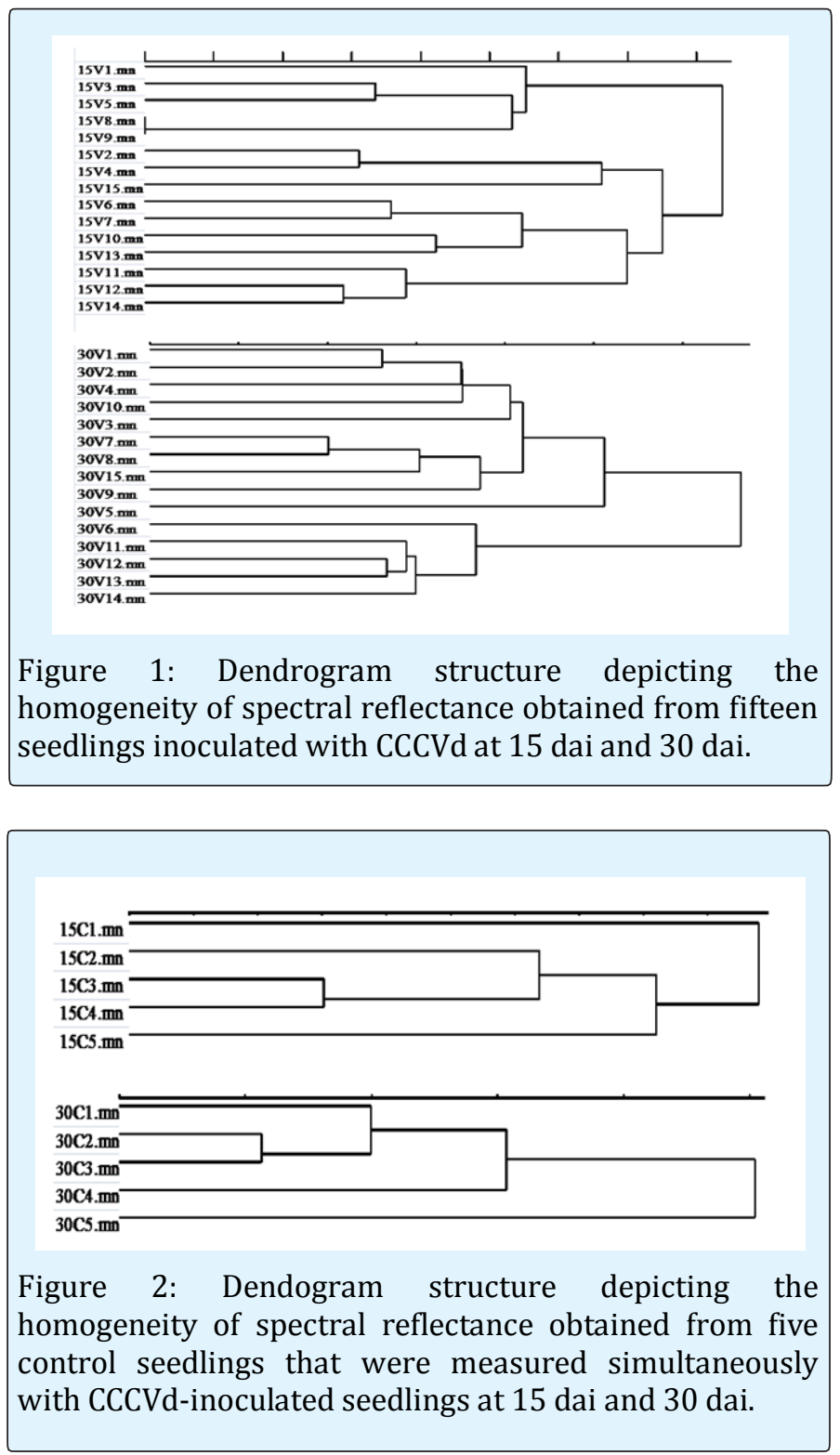

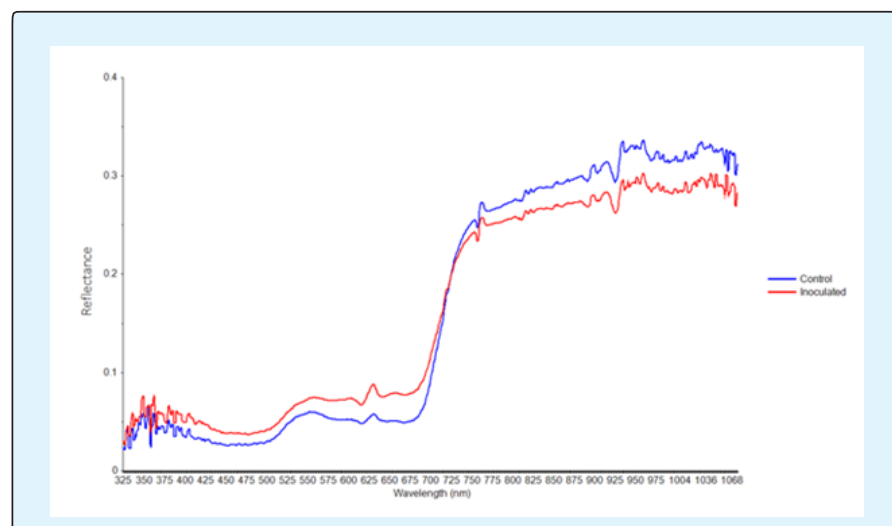

Figure 3: Representative spectral signatures of inoculated and healthy oil palm seedlings were plotted against a range of wavelengths between $325 \mathrm{~nm}$ and $1075 \mathrm{~nm}$.

It was observed that RS value corresponding to spectral band $680 \mathrm{~nm}$ was $35.4 \%$ while that corresponding to spectral band $754 \mathrm{~nm}$ was $-5 \%$ (Table 1). Results clearly indicate that spectral band $680 \mathrm{~nm}$ was sensitive to CCCVd infection while spectral band $754 \mathrm{~nm}$ was insensitive to CCCVd infection. In a similar study, Xu, et al. (2007) [17] characterized the leaf spectra of tomato leaves damaged by leaf minor. They used RS as a spectral parameter to find optimal spectral bands for determining and evaluating different stress severity levels. Knipling (1970) [10] described that when a pathogen attacks a plant, more changes occur on reflectance of the plant at the red region compared to the NIR region due to chlorophyll sensitivity. Our results also clearly show that the far red spectral band $(680 \mathrm{~nm})$ contains much information about plant stress as compared to that of the NIR spectral band $(754 \mathrm{~nm})$. These two spectral bands can be employed to develop a spectral disease index for OS disease. Generally, most of the spectral disease indices have been developed from a combination of sensitive Red and insensitive NIR spectral band sand vice versa. For example, the Difference Vegetation Index (DVI) Richardson and Everitt (1992) [18], this combines an insensitive red band with a sensitive NIR band. Kooistra et al. (2004) [19] described that DVI was influenced by stressed vegetation and its morphology which typically affects light scattering at the NIR region Table 1.

\begin{tabular}{|c|c|c|c|}
\hline $\begin{array}{c}\text { Selected } \\
\text { bands (nm) }\end{array}$ & $\begin{array}{c}\text { Reflectance of } \\
\text { inoculated seedling }\end{array}$ & $\begin{array}{c}\text { Reflectance of } \\
\text { control seedling }\end{array}$ & RS \\
\hline 680 & 0.08 & 0.05 & 35.44 \\
\hline 754 & 0.24 & 0.25 & -5.16 \\
\hline
\end{tabular}

Table 1: Reflectance sensitivity of selected spectral bands 


\section{Open Access Journal of Agricultural Research}

To our knowledge, this is the first work on the application of a hand-held spectroradiometer for screening of CCCVd inoculated seedlings. Two selected spectral bands (680 $\mathrm{nm}$ and $754 \mathrm{~nm}$ ) have not been previously reported at the leaf scale for diagnosing oil palm disease. Future studies should deploy a full-range spectroradiometer $(325-2500 \mathrm{~nm})$ to screen inoculated seedlings. Diagnostic spectral signatures basically depend on host-pathogen interaction. This work will lead to the development of spectral signatures for various variants of CCCVd. A number of sensitive spectral bands could also be identified from these spectral signatures. This work heralds a new chapter in viroid spectroscopy.

In the context of OS disease in Malaysia, it appears plausible to deploy a hand-held spectroradiometer for assessment at the leaf scale (nursery stage). For canopy scale investigation, selected spectral bands could be evaluated using air-borne or space-borne hyper spectral sensor platforms. More work is necessary to standardise a protocol for spectral measurement at the leaf scale. A comprehensive initiative on repeating this experiment with different variants of CCCVd at different ecological environments is suggested. Results obtained from this study could be considered preliminary, but the technique may be considered as promising tool for future studies, especially screening a large number of oil palm planting materials infected with other variants of CCCVd associated to OS disease.

\section{Conclusion and Recommendation}

Leaf reflectance of oil palm seedlings was obtained using a non-imaging hand-held spectroradiometer. Spectral signatures were then developed from CCCVd inoculated and healthy oil palm seedlings and compared. This study was focused on the selection of sensitive and insensitive spectral bands from spectral signatures. Hence, two spectral bands, $680 \mathrm{~nm}$ and $754 \mathrm{~nm}$, were selected based on point of maximum light absorption and point of steep slope at far red and NIR regions, respectively. An appreciable increase in RS (35\%) was observed at $680 \mathrm{~nm}$, while RS decreased up to $5 \%$ at 754 $\mathrm{nm}$. These selected wavebands will be useful in the development of Orange Spotting disease index. This work has demonstrated the use of a non-destructive technique for real-time screening of CCCVd-inoculated seedlings at the leaf scale.

\section{References}

1. Diener T0 (1972) Viroids. Adv Virus Res 17: 295-313.
2. Flores R, Hernández C, Alba Aem DE, Daròs JA, Serio FDI (2005) Viroids and viroid-host interactions. Annu Rev Phytopathol 43: 117-139.

3. Palukaitis $P$ (2014) What has been happening with viroids? Virus Genes 49(2): 175-184.

4. Qi Y, Ding B (2003) Inhibition of cell growth and shoot development by a specific nucleotide sequence in a noncoding viroid RNA. Plant Cell 15(6): 13601374.

5. Flores R, Delgado S, Rodio ME, Ambrós S, Hernandez C, et al. (2006) Peach latent mosaic viroid: not so latent. Mol Plant Pathol 7(4): 209-221.

6. Vadamalai G, Hanold D, Rezaian MA, Randles JW (2006) Variants of Coconut cadang-cadang viroid isolated from an African oil palm (Elaies guineensis Jacq.) in Malaysia. Arch Virol 151(7): 1447-1456.

7. Ding B (2009) The biology of viroid-host interactions. Annu Rev Phytopathol 47: 105-131.

8. Owens RA, Hammond RW (2009) Viroid pathogenicity: One process, many faces. Viruses 1(2): 298-316.

9. Kovalskaya N, Hammond RW (2014) Molecular biology of viroid-host interactions and disease control strategies. Plant Sci 228: 48-60.

10. Forde SCM, Leyritz MJP (1968) A study of confluent orange spotting of the oil palm in Nigeria. J Niger Inst Oil Palm Res 4: 371-380.

11. Wu YH, Cheong LC, Meon S, Lau WH, Kong LL, et al. (2013) Characterization of Coconut cadang-cadang viroid variants from oil palm affected by orange spotting disease in Malaysia. Arch Virol 158(6): 14071410.

12. Vadamalai G, Perera A, Hanold D, Rezaian MA, Randles JW (2009) Detection of Coconut cadangcadang viroid sequences in oil and coconut palm by ribonuclease protection assay. Ann Appl Biol 154(1): 117-125.

13. Thanarajoo SS, Kong LL, Kadir J, Lau WH, Vadamalai G (2014) Detection of Coconut cadang-cadang viroid (CCCVd) in oil palm by reverse transcription loopmediated isothermal amplification (RT-LAMP). J Virol Methods 202: 19-23. 


\section{Open Access Journal of Agricultural Research}

14. Knipling EB (1970) Physical and physiological basis for the reflectance of visible and near-infrared radiation from vegetation. Remote Sens Environ 1: 155-159.

15. Boochs F, Kupfer G, Dockter K, Kuhbauch W (1990) Shape of the red edge as vitality indicator for plants. Int J Remote Sens 11(10): 1741-1753.

16. Walter R, Marie L, Shannon O, Louis H (2002) Remote sensing of barley yellow dwarf and wheat streak mosaic disease in winter wheat canopies. Proc. of the International Conference on Precision Agriculture 6: 160-166.
17. Xu HR, Ying YB, Fu XP, Zhu SP (2007) Near-infrared spectroscopy in detecting leaf minor damage on tomato leaf. Biosyst Eng 96: 447-454.

18. Richardson AJ, Everitt JH (1992) Using spectral vegetation indices to estimate rangeland productivity. Geocarto Int 7(1): 63-69.

19. Kooistra L, Salas EA, Clevers JG, Wehrens R, Leuven RS, et al. (2004) Exploring field vegetation reflectance as an indicator of soil contamination in river floodplains. Environmental Pollution 127(2): 281290. 